\title{
IMPLEMENTASI SISTEM MONITORING KUALITAS AIR BERBASIS INTELLEGENT SENSOR PH DAN TEMPERATUR PADA WTP PNJ
}

\author{
REZA ISTONI \\ Jurusan Teknik Elektro \\ Politeknik Negeri Jakarta \\ Jl. Prof. Dr. G.A. Siwabessy, Kampus UI, Depok 16425 \\ Email: reza.istoni@mail.ru
}

\begin{abstract}
Abstrak. Kualitas air merupakan parameter yang sangat penting dari sebuah WTP. Kualitas air menjadi satu ukuran bahwa produk air dalam kemasan tersebut layak konsumsi dan memenuhi standar yang berlaku. Dengan demikian penelitian mengenai pemantauan kualitas air mutlak diperlukan pada saat ini. Terlebih lagi pada kondisi tingkat pencemaran saat ini dimana saja tergolong tinggi. WTP PNJ merupakan industri pengolahan air bersih siap minum yang berfungsi selama ini sebagai pusat unggulan dalam pelatihan, pengajaran dan juga tempat riset para peneliti, baik dosen, mahasiswa maupun umum. Peralatan yang digunakan untuk mendeteksi dan memonitor kualitas air ini menggunakan alat yang di sebut Intellegent sensor yang dibuat sendiri dan digunakan untuk mendeteksi kadar $\mathrm{pH}$ dan tingkat temperatur pada air. Sedangkan untuk monitoringnya digunakan software LabVIEW. Intellegent sensor secara real time telah berhasil dan teruji mampu mendeteksi dan memonitor kualitas air pada sumber WTP di PNJ berdasarkan $\mathrm{pH}$ dan temperaturnya, lalu mengirimkan data dan dimonitoring secara real time oleh software LabVIEW. $\mathrm{pH}$ yang terdeteksi berada pada nilai rata-rata 4 untuk sumber air WTP, dan temperaturnya berada pada rata-rata $28^{0} \mathrm{C}$. Sedangkan untuk air siap minumnya terukur rata-rata $\mathrm{pH}$ sebesar 7 dan temperaturnya berkisar $24^{\circ} \mathrm{C}$. Berdasarkan hasil monitoring ini dapat dijadikan referensi dalam pengelolaan WTP PNJ.
\end{abstract}

Kata Kunci : kualitas air, kecerdasan sensor, LabVIEW

Abstract. Water quality is an important parameter of a WTP. Water quality is one measure that the bottled water products are worth consuming and meeting the prevailing standards. Thus research on water quality monitoring is absolutely necessary at this time. Especially in the current pollution level conditions where it is high. WTP PNJ is a ready to drink drinking water treatment industry that has functioned as a leading center in training, teaching and research place. The equipment used to detect and monitor water quality uses a device called Intellegent self-made sensor and is used to detect $\mathrm{pH}$ levels and temperature levels in water. As for the monitoring software used LabVIEW. Intelligent sensors in real time have been successful and proven capable of detecting and monitoring water quality at WTP sources in PNJ based on $\mathrm{pH}$ and temperature, then sending data and monitored in real time by LabVIEW software. Detected $\mathrm{pH}$ is at an average of 4 for a WTP water source, and its temperature is at an average of $28^{\circ} \mathrm{C}$. while for drinkable water it is measured on average $\mathrm{pH}$ of 7 and its temperature is $24^{0} \mathrm{C}$. Based on the results of this monitoring can be used as a reference in the management of WTP PNJ.

Keywords: water quality, intellegent sensor, LabVIEW

\section{PENDAHULUAN}

Air bersih merupakan kebutuhan pokok manusia. Oleh sebab itu penyediaan air bersih bagi masyarakat sangat diperlukan. Saat ini air bersih sudah pada level yang cukup memprihatinkan, di mana ketersediaan air bersih khususnya di wilayah perkotaan sudah 
menipis dan juga mahal harganya. Salah satu penyebabnya adalah pencemaran lingkungan. Salah satu cara pencegahan pencemaran air adalah dengan metode pendeteksian dini dari tingkat pencemaran air, yaitu dengan cara melakukan pengambilan sampel air dan melakukan pengujian sampel air tersebut di laboratorium. Cara seperti ini memerlukan peralatan yang lengkap, mahal dan hasilnya tidak bisa cepat.

Berdasarkan Permenkes No.416 Tahun 1990 bahwa kualitas air adalah suatu ukuran kondisi air dilihat dari karakteristik fisik, kimiawi, dan biologisnya. Kualitas air juga menunjukkan ukuran kondisi air relatif terhadap kebutuhan biota air dan manusia. Kriteria mutu air merupakan satu dasar baku mutu air, di samping faktor-faktor lain. Baku mutu air adalah persyaratan mutu air yang disiapkan oleh suatu negara atau daerah yang bersangkutan. Pengukuran air akan lebih akurat jika dilakukan di tempat, karena air berada dalam kondisi yang ekuilibrium dengan lingkungannya. Pengukuran di tempat umumnya akan mendapatkan data mendasar seperti temperatur, $\mathrm{pH}$, kadar oksigen terlarut, konduktivitas dan sebagainya.

Menurut Sukamto (2016) cara untuk memonitoring kualitas air yaitu dengan cara membandingkan dengan kualitas dari perusahaan daerah air minum (PDAM) menggunakan sensor turbidity, sensor $\mathrm{pH}$, dan sensor suhu serta menampilkan data melalui web. Sedangkan menurut Shinta Agmalini (2013) dimana air baku saat ini kalua langsung dari sumbernya banyak mengandung logam berat yang tinggi, bakteri anorganik dan lain sebagainya dengan kandungan cukup tinggi. Perbedaan dengan penelitian yang dilakukan saat ini pada WTP PNJ adalah dengan metode real time antara kualitas sumber air dan air hasil olahan.

Salah satu metode yang sudah diterapkan oleh peneliti adalah dengan mengadakan penelitian kualitas air dengan berbasis smart/intellegent sensor. Sensor adalah sesuatu yang digunakan untuk mendeteksi adanya perubahan lingkungan fisik atau kimia. Intellegent sensor merupakan sebuah device yang dapat mendeteksi data dari fisik, kimia dan biologi, lalu mengkonversi data dari output relay ke peralatan/device monitoring. Intellegent sensor sebenarnya dapat diartikan sebagai sistem peralatan sensor yang yang lebih sensitif, praktis, akurat, low energy, dan low cost. Penelitian dengan menggunakan intellegent sensor sudah dimulai oleh Fauzi Amani, Dkk, (2016) dengan judul Alat Ukur Kualitas Air Minum Dengan Parameter Ph, Suhu, Tingkat Kekeruhan, Dan Jumlah Padatan Terlarut. Dalam penelitian menggunakan sensor dari LM 35, sensor turbidity, dan juga sensor $\mathrm{pH}$. Sistem ini masih menggunakan LCD sebagai displaynya.

Berdasarkan penelitian dari Abdul Fatah, Dkk (2016) selain pencemaran yaitu faktor kekeruhan air. Kekeruhan adalah keadaan di mana transparansi suatu zat cair berkurang akibat kehadiran zat-zat tak terlarut. Sensor kualitas air juga sudah banyak dimulai dibuat diantaranya dari penelitian yang dilakukan oleh Beni Rama, Dkk (2016) dalam tulisannya yang berjudul Fabrikasi Dan Karakterisasi Sensor Konduktivitas Berbasis Teknologi Film Tebal Untuk Analisis Kualitas Air. Di mana Sensor yang dibuat adalah sensor konduktivitas dan sensor temperature.

Menurut Priyani Kusrini (2016), kualitas air salah satu parameternya ditentukan seberapa besar kadar $\mathrm{pH}$ yang terkandung dalam air tersebut. Air murni bersifat netral, dengan pH-nya pada suhu $25^{\circ} \mathrm{C}$ ditetapkan sebagai 7,0., pH berfungsi sebagai indikator untuk reaksi kimia dan biologi dalam metabolisme akuatik. Suhu secara langsung atau tidak langsung sangat dipengaruhi oleh sinar matahari. Suhu air sangat berpengaruh terhadap jumlah oksigen terlarut di dalam air. Jika suhu tinggi, air akan lebih cepat jenuh dengan oksigen dibanding dengan suhunya rendah. Parameter suhu berfungsi sebagai indikator yang dapat meningkatkan atau menurunkan laju metabolik (pertumbuhan) dan mempengaruhi pembiakan dan penetasan telur.

Sistem monitoring untuk kualitas air sudah ada beberapa yang membuat walau hanya sebatas air yang diambil sebagai sampel lalu hasilnya ditampilkan di display atau LCD. Hal ini mendorong penelitian untuk terus dikembangkan tentang kualitas air, baik dari segi sensornya maupun dari monitoringnya. Berdasarkan penelitian dari A Chouder (2013), software LabVIEW sangat cocok untuk pemantauan, pemodelan dan juga simulasi. Jadi software ini sangat mudah dikembangkan. LabVIEW adalah perangkat lunak komputer untuk pemrosesan 
dan visualisasi data dalam bidang akuisisi data, kendali instrumentasi serta automasi industri. Saat ini LabVIEW sudah banyak digunakan diberbagai keperluan yang berhubungan dengan pengolahan data, display data, analisis data, programming dan lain sebagainya. LabVIEW bukan hanya dikembangkan dan digunakan di dunia pendidikan namun juga di gunakan di dunia industri.

Menurut Zulfan Khairil Simbolon (2016) data yang dihasilkan oleh LabVIEW berupa data teks satu baris yang dipisahkan oleh sebuah semicolon antara satu data dengan data lainnya. Setiap data yang diakuisisi disimpan ke dalam sebuah file kemudian untuk akuisisi berikutnya akan menimpa data yang telah disimpan sebelumnya, sehingga sebelum data tersebut ditimpa harus dilakukan pengambilan data tersebut untuk dimasukkan ke dalam database MySQL. Sistem monitoring yang dikembangkan yaitu sistem monitoring secara real time dari sensor $\mathrm{pH}$ dan temperatur dari WTP PNJ sehingga kualitas air produksi dapat dipantau secara akurat.

\section{METODE}

\section{Parameter yang Diteliti/diamati}

WTP PNJ merupakan sebuah representasi industri pengolahan air bersih siap minum yang dikelola oleh Jurusan Teknik Elektro. Selain menghasilkan air bersih juga sebagai sarana pembelajaran dan riset bagi dosen dan mahasiswa PNJ. Kualitas air dapat ditinjau dari beberapa hal, namun parameter yang diimplementasikan untuk dimonitoring pada WTP PNJ dalam penelitian ini adalah:

1) Pengukuran kadar $\mathrm{pH}$ dari sumber air WTP PNJ

2) Pengukuran kadar $\mathrm{pH}$ dari tangki air bersih siap minum

3) Pengukuran suhu/temperatur dari sumber air

4) Pengukuran suhu/temperatur dari tangki air bersih siap minum

5) Akuisisi data dan juga kalibrasi data hasil pendeteksian sensor

6) Hasil pengukuran yang akurat dan real time

\section{Model yang Digunakan}

Model atau desain yang digunakan dalam monitoring kualitas air pada WTP PNJ dapat dilihat pada diagram blok di bawah ini:

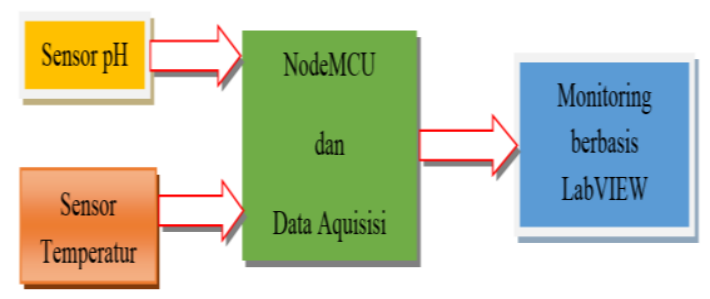

Gambar 1. Model dari Implementasi Intellegent Sensor $p H$ dan Temperatur untuk Monitoring Kualitas Air di WTP PNJ

\section{Metode Implementasi dan State of The Art Penelitian}

Berdasarkan diagram blok dari model penelitian pada gambar 1 di atas maka implementasi penelitian intellegent sensor tentang kualitas air ini dapat di jelaskan sebagai berikut ini:

1) Menggunakan sebuah sensor $\mathrm{pH}$ yang sensitif terhadap kadar $\mathrm{pH}$ dari sumber air.

2) Menggunakan sebuah sensor temperatur yang sensitif terhadap temperatur dari sumber air.

3) Menggunakan NodeMCU sebagai sebuah sistem aquisisi data dari 2 buah sensor yaitu sensor $\mathrm{pH}$ dan sensor temperatur dan bersifat wireless agar mudah dimonitoring oleh 
LabVIEW.

4) Merancang dan menggunakan software LabVIEW sebagai sebuah sistem monitoring kualitas air secara real time dan nirkabel

5) Software LabVIEW digunakan karena memiliki kualitas dan tingkat pengembangan yang mudah, terukur dan teruji.

6) Memasang sistem intellegent sensor di sumber air yang akan dipantau

7) Melakukan akuisisi data dan juga analisis data yang ditampilkan oleh sistem monitoring berbasis LabVIEW.

8) Memastikan sistem smart sensor ini telah diimplementasikan dengan tepat pada WTP PNJ

\section{HASIL DAN PEMBAHASAN}

Penerapan dan Implementasi Sistem Monitoring Pada WTP PNJ

Hasil rancangan alat dan program LabVIEW untuk monitoring WTP PNJ:

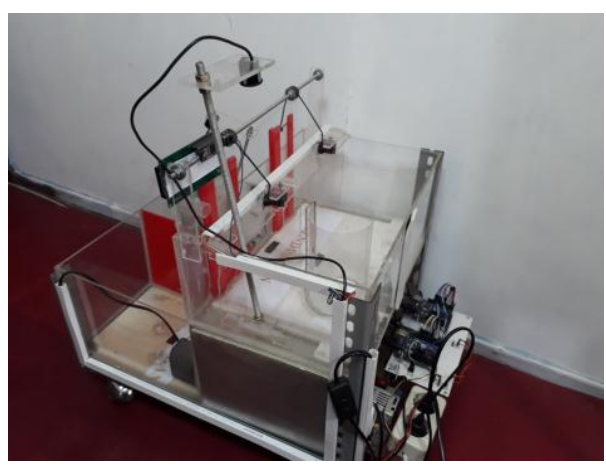

Gambar 2. Alat Intellegent Sensor $\mathrm{pH}$ dan Temperatur untuk Monitoring Kualitas Air Berbasis LabVIEW

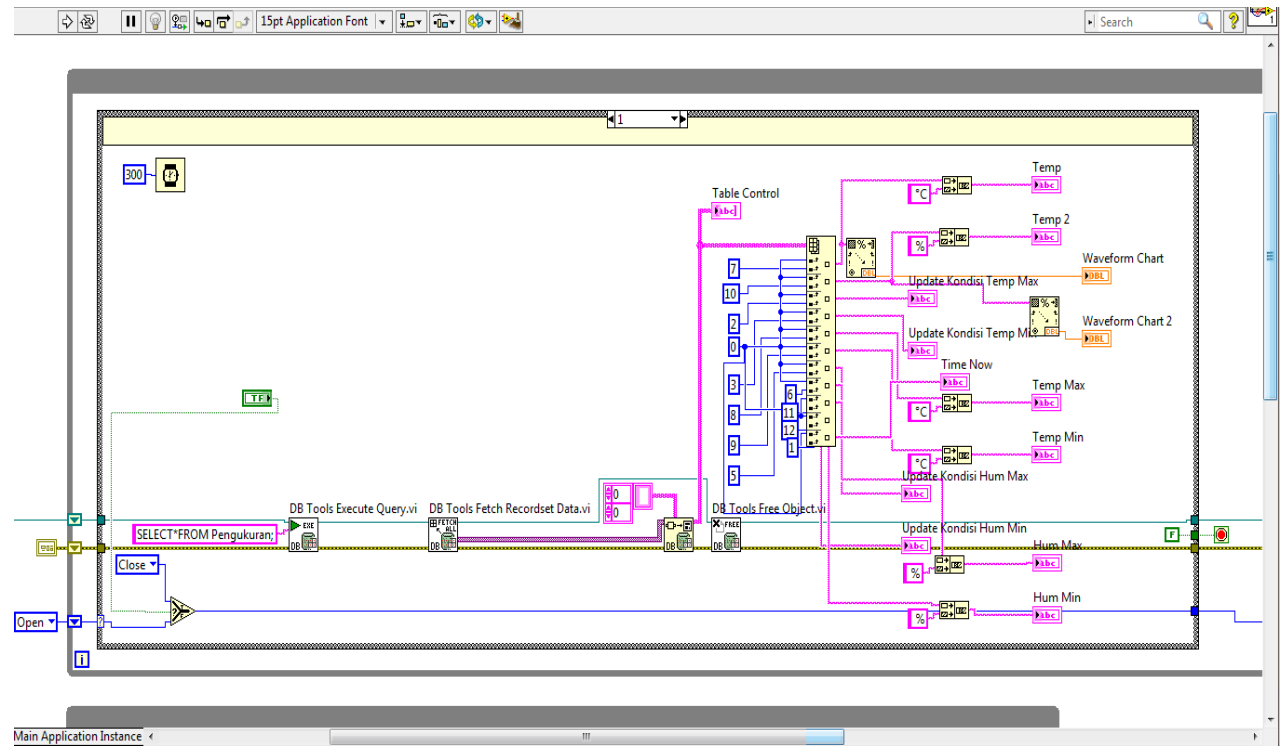

Gambar 3. Blok Diagram Alat Intellegent Sensor pH dan Temperatur untuk Monitoring Kualitas Air Berbasis LabView 


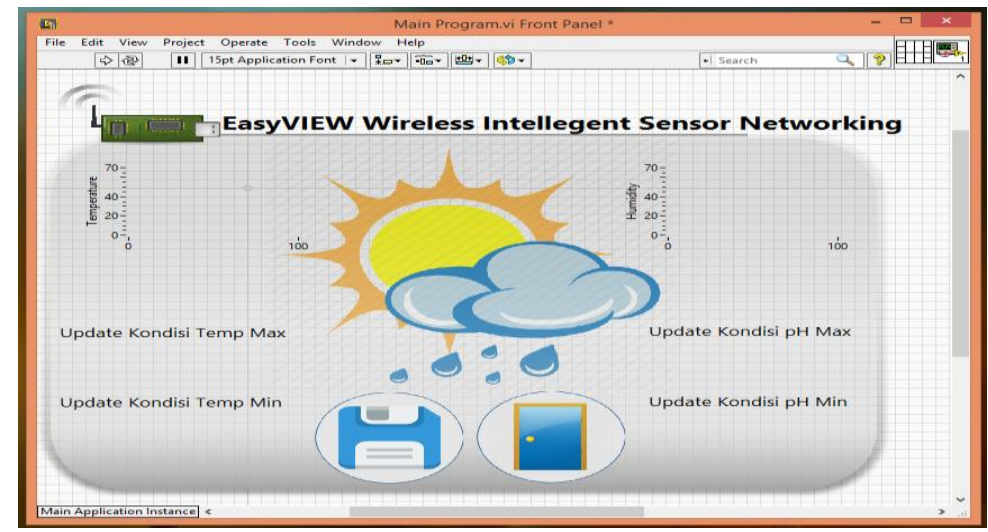

Gambar 4. Sistem Monitoring pada Alat Intellegent Sensor $\mathrm{pH}$ dan Temperatur untuk Monitoring Kualitas Air Berbasis LabVIEW

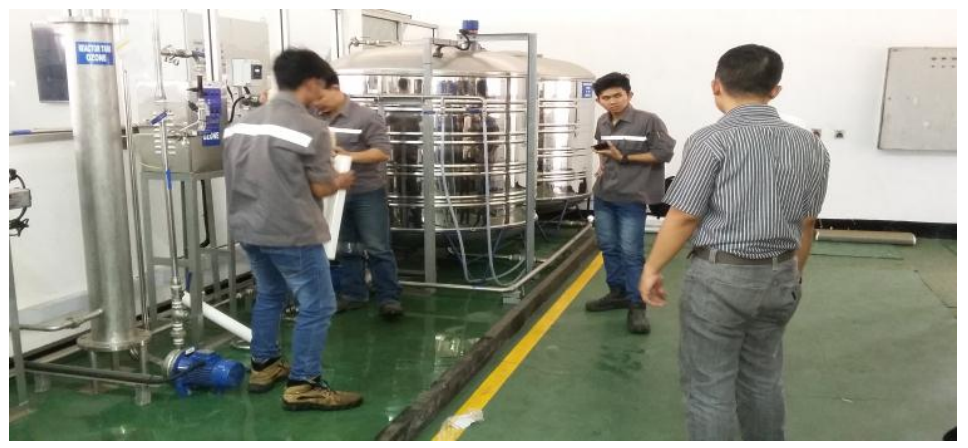

Gambar 5. Implementasi Alat Intellegent Sensor $\mathrm{pH}$ dan Temperatur untuk Monitoring Kualitas Air Berbasis LabVIEW pada WTP PNJ

\section{Hasil Implementasi dan Uji Real Time}

Hasil implementasi alat dalam penelitian Intellegent Sensor $\mathrm{pH}$ dan Temperatur untuk Monitoring Kualitas Air berbasis LabView pada WTP PNJ:

a. Hasil Pengukuran dan Penerapan Sensor $\mathrm{pH}$ dan Temperatur

Tabel 1. Hasil Pengukuran Sensor pH dan Temperatur untuk Kualitas Air pada Sumber Air di WTP PNJ.

\begin{tabular}{ccccc}
\hline No. & Tegangan $(\mathbf{V})$ & $\operatorname{Arus}(\mathbf{m A})$ & $\begin{array}{c}\text { Resistansi } \\
(\mathbf{O h m})\end{array}$ & Suhu $\left({ }^{0} \mathbf{C}\right)$ \\
\hline 1 & 0.65 & 66 & 1303 & 28 \\
2 & 0.7 & 66 & 1301 & 28 \\
3 & 0.65 & 67 & 1303 & 31 \\
4 & 0.65 & 65 & 1303 & 29 \\
5 & 0.65 & 65 & 1301 & 29 \\
6 & 0.71 & 66 & 1301 & 28 \\
7 & 0.72 & 65 & 1302 & 28 \\
8 & 0.71 & 66 & 1300 & 29
\end{tabular}


Faktor Exacta 11 (2): 158-166, 2018

p-ISSN: 1979-276X

e- ISSN: 2502-339X

DOI: $10.30998 /$ faktorexacta.v11i2.2342

Istoni- Implementasi Sistem Monitoring Kualitas.....

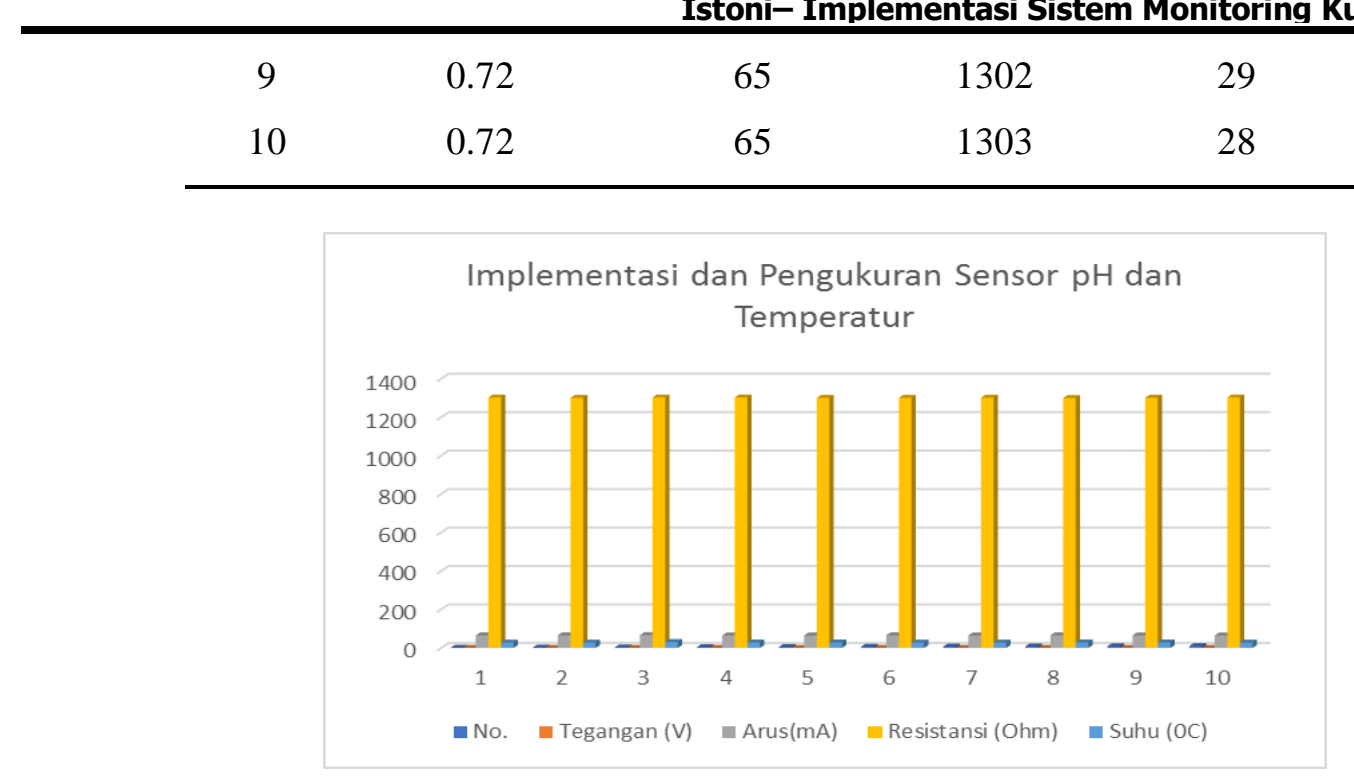

Gambar 6. Grafik Respon Alat Intellegent Sensor pH dan Temperatur untuk Monitoring Kualitas Air Berbasis LabVIEW pada WTP PNJ

b. Implementasi Sistem Monitoring Kualitas Air Secara Real Time

Hasil implementasi kualitas air secara real time terhadap WTP PNJ ditunjukkan dalam hasil berupa tabel berikut ini:

Tabel 2. Hasil Implementasi Alat Pengukur Kualitas Air pada Sumber Air WTP PNJ.

\begin{tabular}{cccc}
\hline No. & Waktu (WIB) & pH & Temperatur \\
\hline 1 & 10.00 & 4.5 & 25 \\
2 & 10.05 & 4.5 & 25 \\
3 & 10.10 & 4.5 & 25 \\
4 & 10.15 & 4.3 & 25 \\
5 & 10.20 & 4.4 & 26 \\
6 & 10.25 & 4.5 & 26 \\
7 & 10.30 & 4.5 & 26 \\
8 & 10.35 & 4.5 & 27 \\
9 & 10.40 & 4.5 & 26 \\
10 & 10.45 & 4.4 & 26 \\
\hline
\end{tabular}

Dari tabel di atas dapat kita gambarkan dengan grafik sebagai hasil respon sensor kualitas air berbasis LabView, seperti gambar berikut ini: 


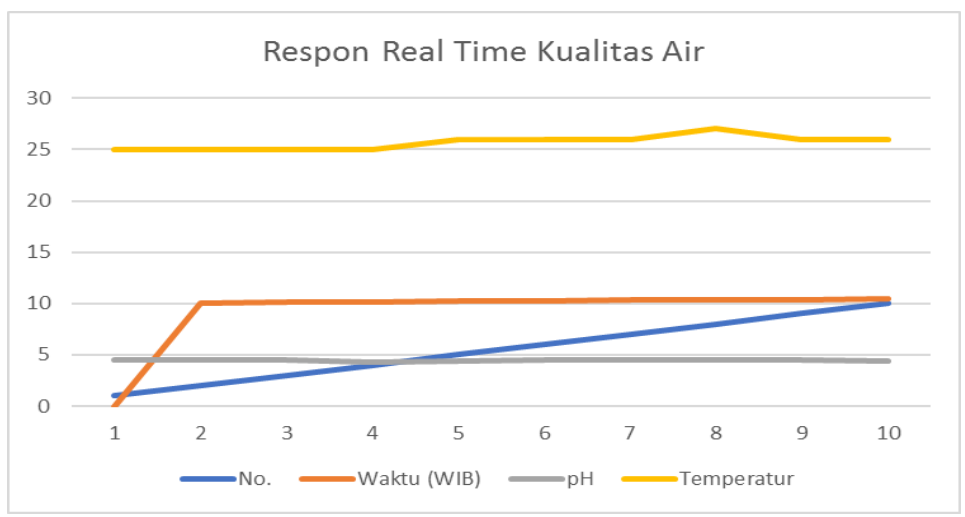

Gambar 7. Grafik Respon Hasil Pengukuran Kualitas Air Berdasarkan pH dan Temperatur berbasis LabView di Raw Water Tank.

Tabel 3. Hasil Implementasi Alat Pengukur Kualitas Air pada Tangki Air Siap MInum WTP PNJ.

\begin{tabular}{cccc}
\hline No. & Waktu (WIB) & pH & Temperatur \\
\hline 1 & 09.15 & 6.5 & 24 \\
2 & 09.25 & 6.5 & 23 \\
3 & 09.40 & 6.8 & 23 \\
4 & 09.55 & 6.8 & 23 \\
5 & 10.10 & 7 & 23 \\
6 & 10.35 & 7 & 24 \\
7 & 10.50 & 7 & 24 \\
8 & 11.15 & 6.9 & 24 \\
9 & 11.30 & 6.9 & 23 \\
10 & 12.15 & 7 & 25 \\
\hline
\end{tabular}

Dari tabel di atas dapat kita gambarkan dengan grafik sebagai hasil respon sensor kualitas air berbasis LabView, seperti gambar berikut ini:

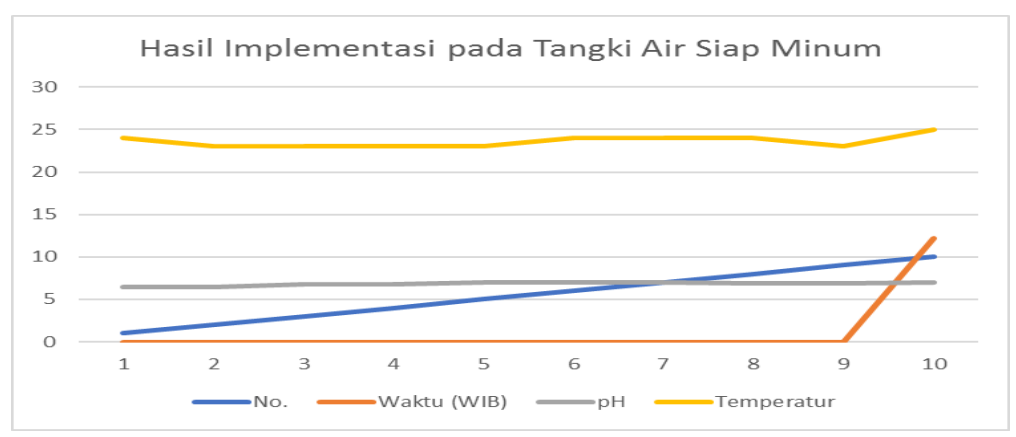

Gambar 8. Grafik Respon Hasil Pengukuran Kualitas Air Berdasarkan pH dan Temperatur berbasis LabView di Clean Water Tank. 


\section{Pembahasan}

Berdasarkan hasil implementasi di atas, alat ini dapat berfungsi dengan baik sebagai sensor untuk memonitor kualitas air pada WTP PNJ secara real time. Hasil implementasi sensor dan data hasil monitoring ini dapat jadi acuan bagi pengelola WTP PNJ untuk memperbaiki dan mengawasi kualitas air agar dapat memenuhi standar AMDK. Di mana hasil yang didapat yaitu $\mathrm{pH}$ air yang ada di sumber WTP PNJ sampai saat ini cukup rendah dari yang seharusnya $6-7$. Oleh sebab itu pengelola WTP PNJ agar dapat mencari sumber air alternative yang lebih baik lagi kualitasnya, sehingga kerja mesin dan filter tidak terlalu berat.

Kadar $\mathrm{pH}$ yang terlalu rendah dapat menyebabkan mesin dan peralatan otomasi akan cepat rusak. Dan temperatur yang terlalu tinggi juga tidak baik bagi kesetabilan mesin WTP. Hal ini disebabkan kolam penampungan sementara tersebut kondisinya terbuka, sehingga menyerap langsung matahari. Hal ini berarti semakin siang kondisi suhu air kolam akan semakin hangat. Faktor lain juga adalah kondisi kolam penampungan yang berlumut sehingga air menjadi lebih keruh dan warnanya hijau, sehingga kondisi filter WTP jadi cepat kotor dan perlu pergantian lebih cepat, secara otomatis akan menambah biaya operasional. Berdasarkan pembahasan di atas maka proses perubahan air baku menjadi siap minum pada WTP tersebut menjadi lebih berat. Kondisi mesin pengolah air juga semakin lama akan mengalami kendala perawatan. Proses ini dapat ditangani dengan penambahan filter alami pada kolam serta pembuatan penutup atau pepohonan agar suhu di kolam tidak terlalu hangat.

\section{PENUTUP}

\section{Simpulan}

Hasil pengolahan air bersih siap minum dari WTP PNJ layak untuk dikonsumsi dan juga sudah lolos uji dari berbagai lembaga. Namun dengan adanya sumber yang tidak terlalu baik dengan kadar $\mathrm{pH}$ yang terlalu rendah (rata-rata 4), serta suhu yang cukup tinggi(rata-rata $28^{\circ} \mathrm{C}$ ) maka sumber WTP ini perlu mendapat perawatan khusus. Perawatan ini dimaksudkan agar dapat mempermudah cara kerja mesin WTP sehingga lebih awet dan biaya operasionalnya lebih murah. Hasil implementasi peralatan monitoring kualitas air pada WTP PNJ ini dapat dijadikan acuan dan rujukan bagi pengelola agar dapat menyusun manajemen yang baik dan terjadwal mengenai permasalahan sumber air dan juga perawatan mesin.

\section{Saran}

Kedepan harus diterapkan beberapa filter hasil penelitian, agar dapat diintegrasikan pada sumber WTP PNJ, sehingga menjadi satu kesatuan pada peralatan WTP PNJ.

\section{DAFTAR PUSTAKA}

Sukamto (2016), Monitoring Perbandingan Kualitas Air Danau dan PDAM Menggunakan Sensor Turbidity, $p H$, dan Suhu berbasis Web, Jurnal JEECAE, Vol.1 No.1.

Shinta Agmalini Dkk. 2013., Peningkatan Kualitas Air Rawa Menggunakan Membran Keramik Berbahan Tanah Liat Alam Dan Abu Terbang Batubara, Jurnal Teknik Kimia No. 2. Vol. 19.

Fauzi Amani, Dkk, 2016., Alat Ukur Kualitas Air Minum Dengan Parameter Ph, Suhu, Tingkat Kekeruhan, Dan Jumlah Padatan Terlarut, JETri, Volume 14, Nomor 1, Agustus 2016, Halaman 49 - 62, ISSN 1412-0372

Abdul Fatah, Dkk., 2016., Rancang Bangun Sistem Alat Ukur Turbidity Untuk Analisis Kualitas Air Berbasis Arduino Uno, Fibusi (JoF), Vol. 4 No.1.

Beni Rama, Dkk., 2016., Fabrikasi Dan Karakterisasi Sensor Konduktivitas Berbasis Teknologi Film Tebal Untuk Analisis Kualitas Air, Fibusi (JoF), Vol. 4 No.1 
Faktor Exacta 11 (2): 158-166, 2018

p-ISSN: 1979-276X

e- ISSN: 2502-339X

DOI: 10.30998/faktorexacta.v11i2.2342

Istoni- Implementasi Sistem Monitoring Kualitas.....

Priyani Kusrini, dkk, 2016., Sistem Monitoring Online Kualitas Air Akuakultur untuk Tambak Udang Menggunakan Aplikasi Berbasis Android, e-ISSN: 2527-9955 doi: 10.14203/jet.v16.25-32

A Chouder, etc, 2013., Monitoring, Modeling and Simulation PV System with LabVIEW. Elsevier. Solar Energi., Univ-msila.dz

Zulfan Khairil Simbolon, 2016., Real Time Monitoring Besaran Listrik untuk Manajemen Energi Gedung Komersial Berbasis Web. Journal JTEPNL. Aceh. 